\title{
Ethnic and demographic variations in HIV/AIDS presentation at two London referral centres 1995-9
}

Introduction

Increasingly effective antiretroviral therapy diagnosis in order to reduce morbidity and prolonged life expectancy. Relatively little is known about how access and disease stage at diagnosis varies by ethnic or demographic factors. ${ }^{1-6}$ These factors were examined in patients at two hospitals in south London.

\section{Methods}

The study population comprised all patients with newly diagnosed HIV/AIDS registered at St Thomas's or Lewisham Hospitals between 1 July 1995 and 31 January 1999. Data from medical records was analysed using sPSs for Windows. Univariate analyses were conducted using $\chi^{2}$ tests. Multiple logistic regression was used to analyse predictor variables for (1) a depressed initial CD4+ count $\left(\leqslant 350 \times 10^{6} / 1\right)$ and $(2)$ an initial HIV/AIDS diagnosis. The models were adjusted for sex, age group, ethnicity, source of referral, and HIV risk factor. The CD4+ model was adjusted for initial HIV status and the HIV/AIDS status model for initial CD4+ count.

\section{Results}

The study population numbered $450 ; 50 \%$ were white ( $74 \%$ homosexual, $10 \%$ female); $38 \%$ were black African ( $99 \%$ heterosexual, $61 \%$ female). The proportion of black African patients rose from $30 \%$ in 1996 to $48 \%$ in $1998 ; 41 \%$ of black Africans were self referred, $11 \%$ were referred by a general practitioners, and $46 \%$ through a hospital department. The comparative figures for whites were $68 \%, 9 \%$, and $18 \%$. In the univariate analysis, source of referral (omitting antenatal clinic referrals) was related to provides a strong rationale for seeking early

ethnicity $(\mathrm{p}<0.001)$, sex $(\mathrm{p}=0.002)$, and risk factor $(\mathrm{p}<0.001)$.

Median CD4+ counts were: all cases $270 \times 10^{6} / 1$; whites $340 \times 10^{6} / 1$; black Africans $200 \times 10^{6} / 1$. Multivariable analysis (see table 1) revealed that black Africans were 3.2 times more likely than whites to present with a $\mathrm{CD} 4+$ count $\leqslant 350 \quad(\mathrm{OR}=3.2,95 \% \mathrm{CI}$ : 1.9-5.2) and people over the age of 35 were 2.8 times more likely than younger people to present with a $\mathrm{CD} 4+$ count $\leqslant 350(\mathrm{OR}=2.8$, 95\% CI: 1.6-5.0). As expected, an initial AIDS diagnosis was a significant predictor $(p<0.001)$. There were no significant interactions between the variables.

Twenty three per cent of patients presented with an initial AIDS diagnosis. This did not vary by ethnicity or risk factor; $33 \%$ of people aged over 35 presented with an AIDS diagnosis compared with $20 \%$ of younger people $(p=0.002)$. The only significant predictors of an initial AIDS diagnosis were source of referral $(\mathrm{OR}=2.6,95 \%$ CI:1.2-5.7) and a depressed CD4+ count (OR=3.1, 95\% CI:3.0-21.7).

\section{Discussion}

The recent marked increase in the proportion of black African patients presenting to these London clinics with newly diagnosed HIV may reflect increased numbers in the population, a greater willingness to seek testing, or a combination of the two. Black Africans show distinct patterns of referral and, together with older patients, are most likely to present with a significantly depressed CD4 count. This study highlights the need to investigate reasons for ethnic and demographic differences in accessing HIV care in order to develop appropriate interventions to reduce delay. The high proportion of patients

Table 1 Effects of selected characteristics on initial CD4+ count ( $\leqslant 350$ and $>350)$ and an initial HIV or AIDS diagnosis

\begin{tabular}{llll}
\hline Characteristic & & Multivariate adjusted OR & $p$ Value \\
\hline Initial CD4+ count & & $2.8(1.6,5.0)$ & $<0.001$ \\
Age group & $>35$ & $3.2(1.9,5.2)$ & $<0.001$ \\
Ethnicity & Black African & $11.2(4.3,28.9)$ & $<0.001$ \\
Initial diagnosis & AIDS & $8.1(3.0,21.7)$ & $<0.001$ \\
Initial HIV or AIDS diagnosis & & $2.6(1.2,5.7)$ & $<0.001$ \\
CD4+ count & $\leqslant 350$ & $17.4(7.8,38.8)$ & $<0.001$ \\
Source of referral & Outpatient & Inpatient & \\
&
\end{tabular}

$\mathrm{n}=376 ; \mathrm{OR}=$ odds ratio. presenting with an AIDS defining illness indicates the need for continued efforts to encourage early testing across all groups.

Funding: This project was funded by a grant from the Special Trustees for St Thomas' Hospital.

Dr B Evans gave advice on interpretation of the data and comments on the draft paper.

Contributors: JS was responsible for data collection, statistical analysis, and preparation of the manuscript; JE was responsible for the study design, study supervision, interpretation of results, and preparation of the manuscript; JCB gave advice on the choice of statistical methods employed, assistance with statistical interpretation, and comments on the draft paper; and $\mathrm{BP}$ contributed to the preparation of the manuscript.

J SAUL J ERWIN

Academic Department of Genitourinary

Medicine, Guy's, King's and St Thomas's

Medical School, St Thomas's Hospital, London SE1 7EH

J C BRUCE

Infectious Disease Epidemiology Unit, London

School of Hygiene and Tropical Medicine,

Keppel Street, London WC1E 7HT

B PETERS

Academic Department of Genitourinary

Medicine, Guy's, King's and St Thomas's

Medical School, St Thomas's Hospital, London SE1 7EH

Correspondence to: Dr J Erwin joerwin@umds.demon.co.uk

1 Low N, Paine K, Clark R, et al. AIDS survival and progression in black Africans living in south London, 1986-1994. Genitourin Med 1996;72:12-16.

2 The Study Group for the MRC Collaborative Study of HIV infection in Women. Ethnic differences in women with HIV infection in Britain and Ireland. AIDS 1996;10:89-93.

3 Brettle, R, Lean C. The natural history of HIV and AIDS in women. AIDS 1991;5:1283-92.

4 Lemp G, Hirozawa A, Cohen J, et al. Survival for women and men with AIDS. F Infect Dis 1992;166:74-9.

5 Del Amo J, Petruckevitch A, Johnson AM, et al. Disease progression and survival in HIV-1 infected Africans in London. AIDS 1998;12: 1203-9

6 Lubega J, Mussen J. Working with clients from African Communities: an assessment of the needs of GUM staff. London: Camden and Islington Community Health Services NHS Trust, June 1996. 